\title{
Comparison of Susceptible and Resistant Maize Hybrids to Colonization by Clavibacter michiganensis subsp. nebraskensis
}

Gladys C. Y. Mbofung, Department of Plant Pathology and Microbiology, Iowa State University, Ames 50011-1020; Jeff Sernett, Commercial Corn Breeder, Monsanto; Harry T. Horner, Department of Genetics, Development and Cell Biology \& Microscopy and Nano-Imaging Facility, Iowa State University, Ames; and Alison E. Robertson, Department of Plant Pathology and Microbiology, Iowa State University, Ames

\begin{abstract}
Mbofung, G. C. Y., Sernett, J., Horner, H. T., and Robertson, A. E. 2016. Comparison of susceptible and resistant maize hybrids to colonization by Clavibacter michiganensis subsp. nebraskensis. Plant Dis. 100:711-717.

Clavibacter michiganensis subsp. nebraskensis causes Goss's bacterial wilt and blight on maize and is managed primarily with C. michiganensis subsp. nebraskensis-resistant hybrids. To understand the mechanisms of resistance to infection by C. michiganensis subsp. nebraskensis, leaves of a susceptible and a resistant maize hybrid at the V4 to V5 developmental stage were wound inoculated with the pathogen. Blight lesion length was monitored, C. michiganensis subsp. nebraskensis colonizing ability was determined, and structural changes were observed using microscopy. Bacterial colonization preceded lesion development that occurred 4 to 5 days postinoculation in both hybrids. Lesion expansion in the susceptible hybrid was associated with a faster rate of $C$. michiganensis subsp. nebraskensis spread and multiplication in the tissues. In the resistant

hybrid, spread and multiplication was reduced $(P<0.0001)$ and, at 16 days postinoculation, became imperceptible. Initially, C. michiganensis subsp. nebraskensis showed a preference for colonization of the metaxylem vessels in both hybrids. Spread from cell to cell was accomplished through disruption of cell walls, presumably from abundance of bacterial cells or enzymatic activity. Morphological responses of the resistant maize hybrid to infection by $C$. michiganensis subsp. nebraskensis were similar to those reported in maize inbred lines that were resistant to Stewart's wilt caused by Pantoea stewartii. Resistance to $C$. michiganensis subsp. nebraskensis was associated with production of a dense matrix in the xylem that deformed and restricted movement of the bacterial cells.
\end{abstract}

Clavibacter michiganensis subsp. nebraskensis (Vidaver and Mandel 1974) (Davis et al. 1984) is the causal agent of Goss's bacterial wilt and blight of maize (Zea mays L.) (Vidaver 1982). As the name suggests, there are two phases to the disease: a wilt phase that is less common and usually occurs on young plants or severely blighted plants, and a leaf blight phase that may occur at any stage of growth (Jackson et al. 2007; Ruhl et al. 2009).

C. michiganensis subsp. nebraskensis occurs in most of the maizegrowing areas of the central region of the United States, where it can cause yield losses of 50 to $60 \%$ depending on the prevailing weather conditions (Ruhl et al. 2009). The disease was observed for the first time in Nebraska in 1969 (Schuster et al. 1972). Prevalence of the disease decreased in the 1980s and 1990s but, during the mid to late 2000 s, it reemerged, causing a serious threat to maize production (Jackson et al. 2007; Robertson and Jesse 2008). Maize hybrid genetics, favorable weather conditions, and increased adoption of reduced tillage have been suggested as possible causes for the recent outbreaks (Givens et al. 2009; Jackson et al. 2007; Langemeier et al. 2012). Its current distribution extends from the southern states of Texas and Louisiana, north to Manitoba and Ontario in Canada, west to Colorado and Wyoming, and east to Michigan and Indiana (Hollier et al. 2014; Jackson et al. 2007; Korus et al. 2011; Malvick et al. 2010; Ruhl et al. 2009).

The major source of inoculum of C. michiganensis subsp. nebraskensis is infested maize residue, and infections predominantly occur through wounds on the maize plant created by heavy rain, hail, or sand blasting during rain storms (Claflin 1999; Jackson et al. 2007;

\section{Corresponding author: G. Mbofung; E-mail: gmbofung @iastate.edu}

*The $\boldsymbol{e}$-Xtra logo stands for "electronic extra" and indicates that two supplementary figures are published online.

Accepted for publication 25 September 2015.

http://dx.doi.org/10.1094/PDIS-04-15-0448-RE

(C) 2016 The American Phytopathological Society
Vidaver 1982). Leaf blight lesions on maize leaves of susceptible hybrids are large ( 6 to $>15 \mathrm{~cm}$ in length), initially light green to yellow, and quickly becoming necrotic (Jackson et al. 2007). In resistant hybrids, the lesions are smaller and the leaf tissue surrounding the lesion is often reddish. Discrete water-soaked spots, called freckles, which occur at the edges of lesions are diagnostic for the disease (Schuster 1975).

Use of tolerant and resistant hybrids is recommended as the best means for managing this disease; no current maize genotype is known to be immune to the pathogen because wounds facilitate infection of these hybrids by the bacterium. Resistance of maize hybrids and inbred lines varied in their reaction to the pathogen, ranging from tolerant to highly susceptible (Calub et al. 1974; Carson and Wicks 1991; Schuster 1975). It was proposed that variation in resistance to $C$. michiganensis subsp. nebraskensis was due to additive gene action, although dominance for resistance has also been reported in highly resistant inbred lines (Treat and Tracy 1990; Treat et al. 1990).

Host plant resistance to bacterial pathogens is primarily achieved through preformed physical barriers such as cell wall structural changes or preformed antimicrobial toxins. Bacterial pathogens capable of overcoming this constitutive defense layer trigger inducible defenses from the host. Host membrane-bound pattern recognition receptor (PRR) proteins interact with pathogen-associated molecular patterns (PAMP), triggering pattern-associated immunity (PTI) in the plant (Jones and Dangl 2006). Bacteria counteract PTI by secreting and injecting effector proteins (avirulence [Avr] proteins) into plant cells. The recognition of the Avr proteins by the host plant resistance proteins usually results in effector-triggered immunity (ETI) (Ade and Innes 2007; Balmer et al. 2013). PTI and ETI result in cell wall reinforcements, production of secondary antimicrobial compounds, and the accumulation of pathogenesis-related proteins (Ade and Innes 2007; Balmer et al. 2013). However, because C. michiganensis subsp. nebraskensis lacks the type III secretory system, it is unlikely to secrete Avr proteins. Presumably, host plant resistance to C. michiganensis subsp. nebraskensis is through the interaction of PAMP and PRR. Although much is known about host-plant defense mechanisms in dicots, very little is known for monocots. The response of 
maize hybrids to infection by $C$. michiganensis subsp. nebraskensis is not well understood but insights into the interaction could enable the development of novel disease management strategies.

Another important bacterial pathogen of maize is Pantoea stewartii (Smith) Dye, which is vectored by the maize flea beetle (Chaetocnema pulicaria Melsh.) and causes Stewart's wilt and leaf blight. Pataky (1985) reported highly correlated reactions of sweet corn hybrids to Goss's wilt and Stewart's wilt. A few years later, Suparyono and Pataky (1989) reported similarities in symptom expression, disease development, and yield loss in both Stewart's and Goss's wilts, suggesting similar resistance mechanisms to both bacterial pathogens. Furthermore, the resistance of sweet corn hybrids to $P$. stewartii was associated with plant height, crop developmental stage at inoculation, and plant genetics (Ivanoff 1936; Ivanoff and Riker 1936). Braun (1982) investigated pathogen-induced ultrastructural changes in $P$. stewartii-susceptible and -resistant maize inbred lines and observed more host-derived vessel-plugging materials in $P$. stewartii resistant seedlings than in susceptible seedlings, and suggested a host response that localized the pathogen. Studies comparing Clavibacter michiganensis subsp. nebraskensis colonization ability in $C$. michiganensis subsp. nebraskensis-resistant and -susceptible hybrids and microscopic visualization of colonized leaf tissues have not been done; however, such studies could elucidate whether resistance mechanisms in maize to C. michiganensis subsp. nebraskensis are similar to those reported for $P$. stewartii.

This study was undertaken to improve our understanding of the nature of resistance in maize to Goss's leaf blight. Specific objectives of the study were to (i) compare Goss's leaf blight severity and the growth rate of $C$. michiganensis subsp. nebraskensis in leaves of a resistant and a susceptible maize hybrid and (ii) visualize and compare morphological and anatomical changes, if any, that occur in a resistant and a susceptible hybrid in response to infection by $C$. michiganensis subsp. nebraskensis.

\section{Materials and Methods}

Maize hybrids, bacterial isolates, and inoculum preparation. C. michiganensis subsp. nebraskensis-resistant (R) maize hybrid DeKalb DKC56-55 and C. michiganensis subsp. nebraskensis-susceptible (S)

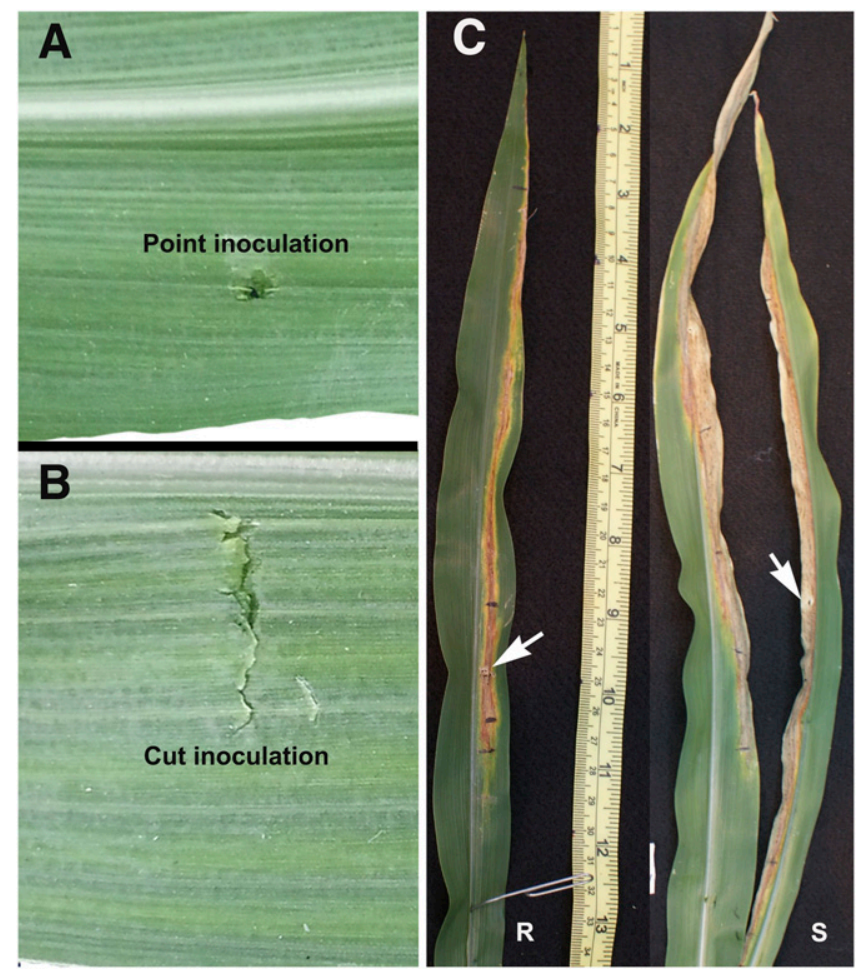

Fig. 1. Sample maize leaves depicting inoculation methods $\mathbf{A}$, point inoculation and $\mathbf{B}$, cut inoculation. $\mathbf{C}$, Leaves of resistant (R) and susceptible (S) hybrids showing lesion development at 22 days after cut inoculation. Arrows indicate site at which leaves were inoculated. hybrid DeKalb DKC55-09 (Monsanto) were used in all experiments. The resistance level of the $\mathrm{R}$ hybrid was rated 2 on a scale of 1 to 9 , where 1 is excellent and 9 is poor; the $S$ hybrid was rated 8 on the same scale (J. Sernett, personal communication). A pathogenic rifampicin-resistant strain of $C$. michiganensis subsp. nebraskensis, 91-R (obtained from C. Block; United States Department of Agriculture Plant Introduction Station, Ames, IA), was used in all experiments. Strain $91-\mathrm{R}$ was originally recovered from maize leaves with characteristic symptoms of Goss's leaf blight from fields in Iowa and was shown to be virulent on maize in subsequent pathogenicity experiments. The isolate was streaked from stock cultures maintained on silica gel at $-20^{\circ} \mathrm{C}$ onto nutrient broth-yeast extract (NBY; amended with of rifampicin at $50 \mathrm{mg} /$ liter) agar plates and incubated for $72 \mathrm{~h}$ at $25^{\circ} \mathrm{C}$. Cell suspensions were prepared by flooding NBY plates with phosphatebuffered saline (PBS, pH 7.0) solution and the final inoculum concentrations were adjusted to $10^{6}$ cells $/ \mathrm{ml}$ with a spectrophotometer (absorbance at $600 \mathrm{~nm}=0.04$ ).

Leaf blight lesion expansion. Four experiments were conducted in the Iowa State University Plant Pathology and Microbiology greenhouse in Ames to compare leaf blight severity by measuring lesion lengths on both the $\mathrm{S}$ and the $\mathrm{R}$ hybrids. Seed of the two hybrids were sown in a steam-sterilized potting mix of peat moss-metro mixcoarse perlite (4:3:4) in $25.4 \mathrm{~cm}$ pots $(1 \mathrm{seed} / \mathrm{pot})$. The plants were grown to crop developmental stage V4 to V5, at which plants have 4 to 5 visible leaf collars (Abendroth et al. 2011), and the fourth and fifth leaves on each plant were inoculated either by a cut- or point-inoculation method (Fig. 1A and B). For both methods, a wound was created midway between the leaf tip and the leaf sheath using a sterile scalpel. In the point-inoculation method, a wound was made on a single major vein whereas, for the cut-inoculation method; an incision was made across three major veins to simulate the damage associated with hail injury on leaves in the field. Using a $25-\mu 1 \mathrm{Ham}-$ ilton syringe (Hamilton Co., Reno, NV), $20 \mu l$ of inoculum (91-R alone at $10^{6} \mathrm{CFU} / \mathrm{ml}$ ) was gently placed on each wound. Randomization of plants was done only after the drop of inoculum had completely dried on the wounds, and the inoculated plants were incubated on the greenhouse bench with a 14-h photoperiod until appearance of symptoms.

The set-up was a two-by-two factorial experiment arranged in a completely randomized design with 10 replications. Pots were watered daily at soil level, and plants were fertilized once a week with NPK (15-5-15) Miracle-Gro liquid fertilizer (The Scotts Co., Marysville, $\mathrm{OH})$ supplemented with $\mathrm{Ca}\left(\mathrm{NO}_{3}\right)_{2}$ and $\mathrm{MgSO}_{4}$ at the rate of 43 and $22 \mathrm{~g} /$ liter, respectively. Lesion length was measured on each of the two inoculated leaves per plant, starting at 7 days postinoculation for the first two biological replications and at 4 days postinoculation for the last two biological replications, and continuing every 4 to 5 days until 28 days postinfection (dpi). Total lesion length at each time point was defined as the maximum length of visible chlorotic and necrotic tissue on either side of the inoculation site. Proximal lesion length was defined as the length of the visible lesion from the site of inoculation to the leaf sheath, and distal lesion length was defined as the length of the lesion from the inoculation site to the leaf tip. The first two experiments were set up in December 2012 and March 2013, while experiments 3 and 4 were set up in January and May 2013, respectively. Temperature in the greenhouse averaged $24.5^{\circ} \mathrm{C}$ for all experiments, while relative humidity $(\mathrm{RH})$ averaged $27 \%$ in December, January, and March and 65\% in May. Lesion length for experiments 1 and 2 was recorded as repeated measures over time while lesion length in experiments 3 and 4 was rated on leaf samples that were later used for determination of bacterial titer.

Movement and colonizing ability of $C$. michiganensis subsp. nebraskensis. Three experiments were set up in the Iowa State University Plant Pathology greenhouse in Ames. Experiments 1 and 2 were set up in January and May 2013, respectively, and ran concurrently with experiments 3 and 4 that measured leaf blight lesion expansion (previous), while experiment 3 was set up in August 2014. The average temperature and $\mathrm{RH}$ in the greenhouse was 
$24.5^{\circ} \mathrm{C}$ and a mean $\mathrm{RH}$ of $27 \%$ for experiment 1 , and $26^{\circ} \mathrm{C}$ and $64 \%$ for experiments 2 and 3 . All plants were subjected to a photoperiod of $14 \mathrm{~h}$. Seed of the $\mathrm{S}$ and R maize hybrids were sown (1 seed/pot) in the same soil mix as already described and allowed to grow to the crop developmental stage V4 to V5. In the first two experiments, the fourth leaf on each plant was inoculated with $20 \mu \mathrm{l}$ of inoculum (91-R alone at $10^{6} \mathrm{CFU} / \mathrm{ml}$ ) by either the cut- or point-inoculation method, as already described. The control plants were inoculated with only PBS. The set-up for the two experiments was a two-bytwo factorial experiment in a completely randomized design with three replications. Three leaves (one leaf per plant) per hybrid per inoculation method were randomly sampled at 4, 10, 16, 22, and 28 dpi and taken to the laboratory for processing. In the third biological replicate, the experimental set-up was similar, except the leaves were cut inoculated and six leaves (one per plant) instead of three were randomly collected per sampling period per hybrid for processing in the laboratory.

Each leaf was washed once, separately, in sterile distilled water, surface disinfested by complete immersion in $70 \%$ ethanol for 20 to $30 \mathrm{~s}$, and immediately rinsed thoroughly, twice, with sterile distilled water. The leaves were blotted dry with sterile paper towels and leaf subsamples of $2 \mathrm{~cm}$ in diameter were cut out progressively at $5,10,15$, and $20 \mathrm{~cm}$ from both sides of the inoculation site using a sterile cork borer, for a total of eight leaf discs per sample. Individual leaf discs were homogenized in $2 \mathrm{ml}$ of PBS with the aid of a mortar and pestle. Ten-fold serial dilutions were prepared per leaf disc, and 0.1-ml aliquots from three different dilutions were plated on six replicate plates of NBY medium amended with rifampicin at $50 \mathrm{mg} / \mathrm{liter}$ in the first two experiments. For experiment 3, dilutions were plated using the drop-plate method adapted from Chen et al. (2003). In brief, after homogenization, 10-fold serial dilutions were prepared in sterile deep-well enzyme-linked immunosorbent assay plates (similar to PlateOne, $2 \mathrm{ml}$ by 96-deep well plates; USA Scientific, Ocala, FL). Six 10- $\mu$ l drops of three different dilutions were plated on two replicate plates of NBY+rif media using a multichannel pipettor. A total volume of $0.12 \mathrm{ml}$ per dilution was drop plated on each plate. All plates were incubated in the dark at $25^{\circ} \mathrm{C}$ and the bacterial titer was determined 5 days later, and then later at 10 days. The number of CFU/leaf disc for the drop-plate method was calculated as follows:

$$
\frac{\mathrm{CFU}}{\text { leaf disc }}=\frac{\text { total } \mathrm{CFU}}{\text { number of drops counted } \times \frac{\text { dilution }}{1 \text { drop }}} \times \frac{2 \mathrm{ml}}{1 \text { leaf disc }}
$$

The number of CFU for the dilution-plate method was calculated as follows:

$$
\frac{\mathrm{CFU}}{\text { leaf } \operatorname{disc}}=\text { number of colonies } \times \text { dilution } \times 0.1 \mathrm{ml} \times 2 \mathrm{ml}
$$

The data were recorded as actual CFU/leaf disc and later converted to $\log _{10}$ scale for analysis.

Maize hybrid morphological and anatomical responses to infection by $C$. michiganensis subsp. nebraskensis using microscopy. Scanning electron microscopy (SEM) was used to observe and compare the $C$. michiganensis subsp. nebraskensis-induced structural changes in inoculated maize leaf tissues. The $\mathrm{S}$ and $\mathrm{R}$ maize hybrids were sown as already described. At the V4 to V5 crop developmental stage, leaves 4 and 5 were inoculated by the point- and cut-inoculation methods with $20 \mu \mathrm{l}$ of inoculum (91-R at $\left.10^{6} \mathrm{CFU} / \mathrm{ml}\right)$. The set-up was a two-by-two factorial experiment arranged in a completely randomized design with three replications.

The experiment was repeated four times: October 2012, January 2013, April 2013, and August 2013. In the first two experiments, three leaves per treatment were sampled at 4 and 10 dpi whereas, in the last two experiments, leaf sampling was done at 10 dpi only. Three inoculated leaves were randomly collected and subsamples of about $20 \mathrm{~mm}$ long were cut from within the lesions (chlorotic and necrotic, with freckles), from lesion edges (and chlorotic areas), and at $1 \mathrm{~cm}$ from lesion edges (green tissue with no water soaking and chlorosis). The subsamples were immediately fixed in formalinacetic acid-alcohol (Jensen 1962) in the greenhouse, before being taken to the laboratory and stored at $4{ }^{\circ} \mathrm{C}$ until processing. Leaf subsamples were dehydrated in an ethanol series beginning at $50 \%$ ethanol and ending in ultrapure ethanol. Samples were dried in a critical point apparatus (Denton Vacuum, LLC, Mooreston, NJ) using liquid carbon dioxide. Each dried leaf sample was sandwiched between two strips of clear packing tape, pressed firmly together, and quickly pulled apart to produce a fracture consisting of two complementary internal leaf faces. These faces were attached face-side up to a large SEM aluminum plate, sputtered coated in a Denton vacuum system (Denton Vacuum, LLC) with a 10-nm layer of palladium-gold (60: 40), and observed and digitally imaged using a JEOL 5800 SEM (JEOL Ltd., Tokyo) at $13 \mathrm{kV}$.

Samples for viewing under the compound microscope were prepared by cutting leaf samples of 20 by $20 \mathrm{~mm}$ from within lesions, at lesion edges, and at $1 \mathrm{~cm}$ from lesion edges and stored immediately in PBS. Longitudinal and transverse sections of the leaves were prepared for observation using a Vibratome 1000 Plus Sectioning system (The Vibratome Co., St Louis). The section cut option was set to single cuts and the thickness was set to 50 or $100 \mu \mathrm{m}$. The sectioning block speed, amplitude, and sectioning blade angle were adjusted according to the manufacturer's specifications. Finally, the movement of the stage was set to maximum for ease of control. Leaf sections (50 to $100 \mu \mathrm{m}$ thick) were cut in a distilled water bath set at the required temperature from leaf subsamples of about 2 by $2 \mathrm{~mm}$. Leaf sections were immediately mounted on microscope slides in a drop of Aqua-Mount (Polysciences Inc., Warrinton, PA) and viewed under the compound microscope for differences in cell wall thicknesses and presence of tyloses. Leaf subsamples were processed within $3 \mathrm{~h}$ of sampling from the greenhouse to limit tissue deterioration.

Statistical analysis. Data from leaf blight lesion expansion and C. michiganensis subsp. nebraskensis population densities were subjected to analysis of variance separately using the generalized linear mixed model (PROC MIXED) of SAS (SAS Institute, Cary, NC). For analysis of data from lesion expansion, hybrid and inoculation methods were considered as fixed effects, while plant and leaf were treated as random effects. For analysis of $C$. michiganensis subsp. nebraskensis colonization distance and population density, C. michiganensis subsp. nebraskensis incidence in the leaf was first evaluated as a binary response model by converting responses at each leaf disc position into a 0 or 1 variable (no C. michiganensis subsp. nebraskensis detected or $C$. michiganensis subsp. nebraskensis present, respectively) to evaluate response variables that contained many zeros as well as large titer counts. SAS PROC FREQ was used to select model terms for further analysis based on model significance. Bacterial titer data were logtransformed (base 10) and subjected to an analysis of variance. Run, hybrid, inoculation method, dpi, and distance from inoculation site on leaf were treated as fixed effects, and leaf was considered to be random. When mean population counts for both inoculation methods were analyzed together, there was a significant difference between experimental runs. However, when only data from the cut-inoculation method were analyzed, there was no significant difference between experiments and the population density trends over time in the three experiments were similar. Data from the three experiments were then combined and analyzed. The statistical analyses showed significant interactions among hybrid, distance from inoculation point site, position of sample with respect to inoculation site, and sampling period (dpi). The data were then sorted by dpi and reanalyzed.

\section{Results}

Leaf blight lesion expansion. Blight symptoms were visible on leaves at 4 to $5 \mathrm{dpi}$ for both hybrids and increased in size significantly over time. Mean proximal lesion length in the $\mathrm{S}$ hybrid was considerably greater than in the $\mathrm{R}$ hybrid for both inoculation methods over time $(P<0.0001$; Figs. $1 \mathrm{C}$ and $2 \mathrm{~A})$. The differences between the $\mathrm{R}$ and $\mathrm{S}$ hybrid in lesion elongation were observed as early as $4 \mathrm{dpi}$. Generally, there was a slower onset of lesion elongation with the point inoculation as opposed to the cut inoculation for both $\mathrm{R}$ and S hybrids (Fig. 2A, B, and C). The progress of mean distal and total lesion length for the $\mathrm{S}$ hybrid was slower than in the $\mathrm{R}$ hybrid (Fig. $2 \mathrm{~B}$ and $\mathrm{C}$ ). At $28 \mathrm{dpi}$, lesion length development was arrested in the 
$\mathrm{R}$ hybrid compared with the $\mathrm{S}$ hybrid, in which most of the leaf blade was blighted (Fig. 2A, B, and C).

Comparison of colonizing ability of $C$. michiganensis subsp. nebraskensis in $\mathbf{R}$ and $\mathbf{S}$ maize hybrids. Colonization and multiplication of $C$. michiganensis subsp. nebraskensis, as defined by mean bacterial titer in maize leaf tissue over time from the inoculation site, differed between hybrids $(P<0.0001$; Table 1$)$. Mean bacterial titer in leaf tissue over time was also observed to be significantly influenced by position (distal or proximal) and distance from the inoculation site (Table 1 ). This interaction was statistically significant at 10 dpi $(P<0.0325)$. Analysis of $C$. michiganensis subsp. nebraskensis populations across all sampling distances at different sampling periods showed mean bacterial titer in the $\mathrm{S}$ hybrid was several-fold higher than in the R hybrid (Fig. 3).

The point inoculation resulted in lower titers but led to greater variations in population densities across treatments compared with the cut-inoculation method at 4 and 10 dpi $(P<0.0001$ and $P=$ 0.0048; Supplementary Fig. S2). Therefore, only data obtained with the cut-inoculation method are presented in the analysis. When the mean C. michiganensis subsp. nebraskensis titer per leaf disc was analyzed by dpi for the cut-inoculated plants only, hybrid differences were obvious before 4 dpi and continued to be significant all through the experiment $(P=0.0001)$. At $4 \mathrm{dpi}$, the bacteria had moved 10 and $15 \mathrm{~cm}$ on the proximal side of the site of inoculation for the $\mathrm{R}$ and the $\mathrm{S}$ hybrids, respectively. C. michiganensis subsp. nebraskensis multiplied rapidly at the inoculation site and then spread toward both the

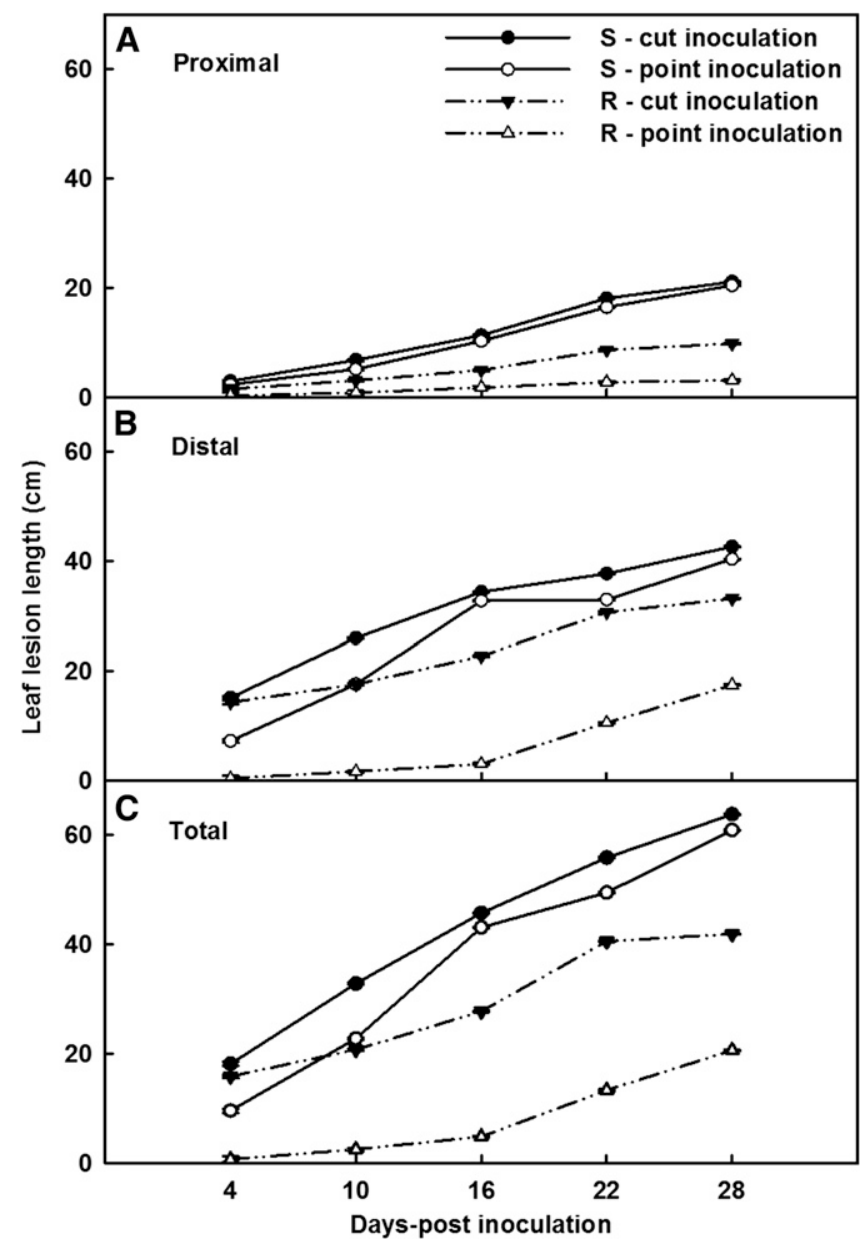

Fig. 2. Mean Goss's leaf blight lesion severity $(n=20)$ in susceptible (S) and resistant (R) maize hybrids infected with Clavibacter michiganensis subsp. nebraskensis using point- and cut-inoculation methods. Repeated measurements of Goss's leaf blight lesion length were done from 4 to 28 days postinoculation. A, Mean proximal lesion length; $\mathbf{B}$, mean distal lesion length; and $\mathbf{C}$, mean total lesion length were obtained from combined data of experiments 1 and 2 . Bars indicate standard errors. proximal and distal ends of the leaves in both the $\mathrm{S}$ and $\mathrm{R}$ hybrids (Fig. 3). Higher bacterial titer and distance moved within the leaf were recorded for the distal end of the inoculation compared with the proximal end at $4 \mathrm{dpi}$ for both hybrids (Fig. 3). Bacterial titers decreased as the distance from inoculation site increased for both hybrids at 4 dpi only (Fig. 3). C. michiganensis subsp. nebraskensis colonization in the distal end of the inoculation site was consistently similar for both $\mathrm{S}$ and $\mathrm{R}$ hybrids while colonization of the proximal end was slower for the $\mathrm{R}$ hybrid. Mean $C$. michiganensis subsp. nebraskensis titers in the $\mathrm{R}$ hybrid were always significantly lower than in the S hybrid toward the proximal end of the inoculation site in all the experiments (Fig. 3).

Maize hybrid morphological and anatomical responses to infection by $\boldsymbol{C}$. michiganensis subsp. nebraskensis. Compared with the uninoculated controls (Fig. 4A and D), cellular contents of the mesophyll of inoculated tissues of $\mathrm{R}$ and $\mathrm{S}$ hybrids at 10 dpi were disorganized and individual organelles were not distinguishable within cells (Fig. 4B and E). The bundle sheath cells were still intact in the $\mathrm{R}$ hybrid when bacteria were limited to the vascular bundles (Fig. 4F) compared with the S hybrid (Fig. 4C). In the R hybrid, xylem vessels were filled with bacteria, while the neighboring bundle sheath and mesophyll cells contained very few bacteria (Fig. 4F). Disorganization of the cytoplasm seemed to be accompanied by bacterial colonization for both hybrids (Fig. 4B and C, insert).

Bacterial cells found in the mesophyll and the intercellular spaces of both hybrids seemed to be free of the amorphous matrix (Fig. 5A and D). Bacteria found in the xylem of the $S$ hybrid in samples taken from within leaf blight lesions were clumped but were very distinguishable (Fig. 5B). In the R hybrid, C. michiganensis subsp. nebraskensis bacteria within the xylem vessels in samples taken from within the blight lesions were embedded in an amorphous matrix that appeared to clump them together (Fig. 5E). C. michiganensis subsp. nebraskensis cells in this matrix appeared deformed (Fig. 5F) and were discernible only at higher magnifications compared with those in the S hybrid (Figs. 5C). This amorphous matrix was absent around bacteria in xylem vessels of samples taken at $1 \mathrm{~cm}$ from the lesion edge in both hybrids (data not shown).

\section{Discussion}

This study is the first to compare Goss's leaf blight severity as defined by lesion length development over time, and $C$. michiganensis subsp. nebraskensis colonizing ability and population growth within leaf tissues by estimating bacterial titers along the leaves from inoculation sites in an $\mathrm{S}$ and an $\mathrm{R}$ maize hybrid. A comparison of the morphological and anatomical changes that occurred in response to infection by $C$. michiganensis subsp. nebraskensis in both hybrids was also accomplished. The two hybrids were significantly different for every response variable that was assessed. Leaf blight was more severe in the S hybrid than in the R hybrid, as demonstrated by longer lesions and higher bacterial titer before $10 \mathrm{dpi}$. The onset of lesions was slower in the $\mathrm{R}$ hybrid and blight lesion progress in the $\mathrm{R}$ hybrid

Table 1. Results of analysis of variance of mean bacterial titer $(n=9)$ in susceptible and resistant hybrids on four sampling dates after inoculation with approximately $10^{4}$ cells of Clavibacter michiganensis subsp. nebraskensis ${ }^{\mathrm{a}}$

\begin{tabular}{lrrrr}
\hline & \multicolumn{4}{c}{$\boldsymbol{P}>\boldsymbol{F}$} \\
\cline { 2 - 5 } Effects & \multicolumn{1}{c}{ 4 dpi } & 10 dpi & 16 dpi & 22 dpi \\
\hline Run & 0.3994 & $<0.0001$ & 0.0106 & 0.5480 \\
Hybrid & $<0.0001$ & $<0.0001$ & $<0.0001$ & $<0.0001$ \\
Position $^{b}$ & $<0.0001$ & $<0.0001$ & $<0.0001$ & $<0.0001$ \\
Hybrid $\times$ position $\times$ distance & 0.2917 & 0.0325 & 0.0243 & 0.0379 \\
\hline
\end{tabular}

a Data for bacterial titers were obtained from three biological replicates. Plants were grown to V4 developmental stage and inoculum was introduced at a cut made across three adjacent leaf veins for cut inoculation on V4 and V5 leaves. Three leaves were sampled per treatment per sampling period, and leaf discs were punched out at intervals of $5 \mathrm{~cm}$ on proximal and distal sides of inoculation site for a total of eight positions used to determine bacterial titers; dpi $=$ days postinoculation.

b Proximal or distal with respect to inoculation site. 
slowed down considerably between 4 and 10 dpi, implying a plantinduced mechanism of reduction or inhibition of colonization by the bacteria in the leaves of this hybrid.

The point inoculation resulted in lower titers but led to greater variations in population densities across treatments compared with the cut-inoculation method. The point inoculation was indicative of an insect-vectored infection while the cut inoculation was a simulation of infection through wounds caused by sand blasting, wind, or hail damage under field conditions. Although lesion length expansion over time was similar for both methods in each hybrid, the cutinoculation method was easier to implement and less time consuming. It also provided a larger surface area for most of the inoculum to be absorbed into the leaf, thereby limiting the variation among initial inoculum densities within wounds. This method is recommended for uniform inoculation and subsequent studies of this type and even for screening maize germplasm for resistance in the future.

In all experiments, the interval between inoculation and appearance of first symptoms was never more than 5 days. This interval has been termed the endophytic or latent phase (Smidt and Vidaver 1986). Hence, the $C$. michiganensis subsp. nebraskensis infection process may consist of an initial endophytic colonization phase, during which the bacteria multiply abundantly to reach a critical mass. The symptom-inducing (leaf blight) phase could be initiated by the high density of bacteria in the leaf tissues and possibly by the secretion of some virulence factor by $C$. michiganensis subsp. nebraskensis.
A comparable biphasic infection process was also noted in the closely related subsp. michiganensis, that is a pathogen of tomato (Chalupowicz et al. 2012).

Leaf lesion expansion in the $\mathrm{S}$ hybrid was always associated with a faster rate of bacterial spread and multiplication toward both the distal and proximal ends of the leaf. The ability of $C$. michiganensis subsp. nebraskensis to access or multiply in the leaf tissues of the $S$ hybrid was not restricted; however, it was greatly affected in the $\mathrm{R}$ hybrid. This restriction could be clearly noted from 4 to $22 \mathrm{dpi}$, after which lesion expansion did not change considerably through the end of the experiments. These data imply that the mechanisms of resistance became effective very early on, before $4 \mathrm{dpi}$. However, the mechanisms were only effective on the proximal side of the inoculation site because the progress of lesions toward the distal side was unimpeded.

The smaller lesions and lower titers observed in the R hybrid may be the result of many factors that contribute to defense mechanisms in the maize plant. For example, maize plants that are resistant to certain fungal pathogens have been shown to rapidly oxidize their phenolic contents to promote lignification and suberization of cell walls. This plant resistance mechanism is thought to be responsible for cell death and the sealing off of the infected region, thereby blocking further movement of the pathogen (Beckman 2000). In maize leaf tissues that were infected with Colletotrichum graminicola, an accumulation of anthocyanins in the tissues surrounding lesions was inversely

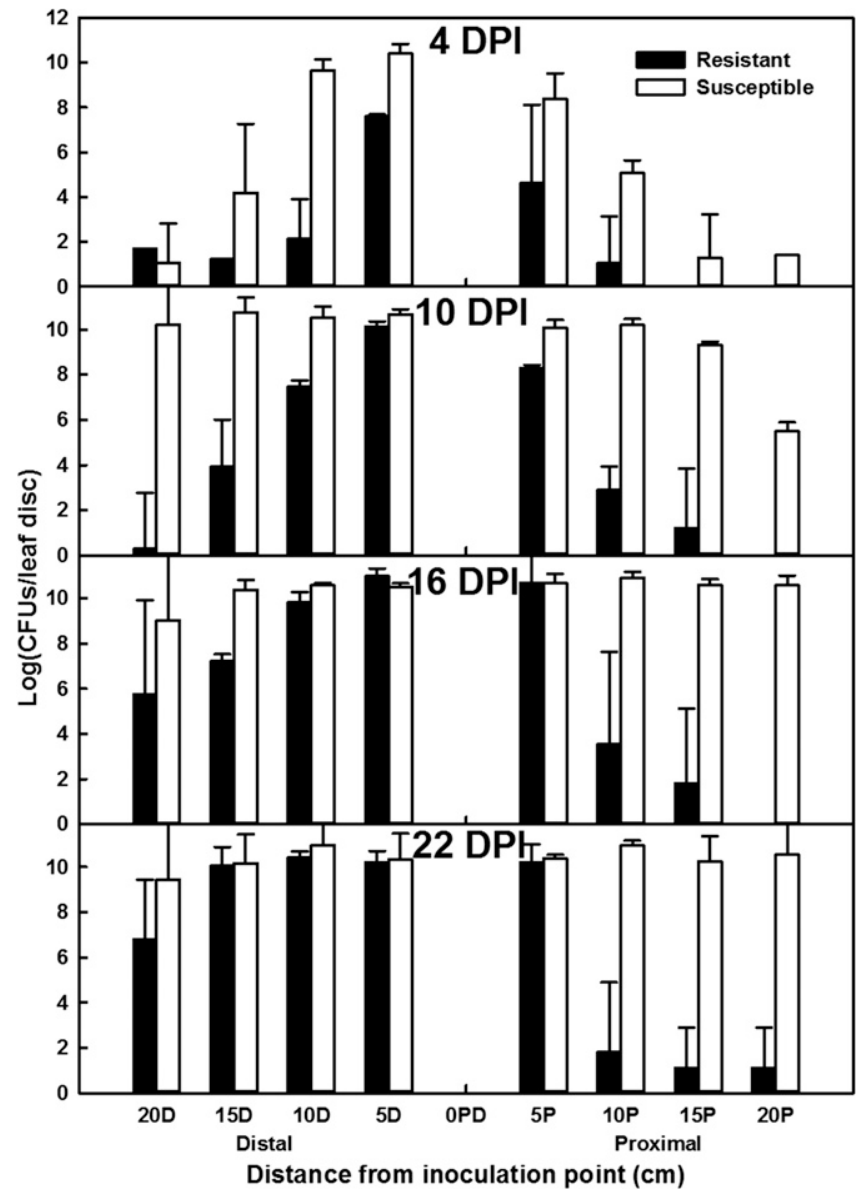

Fig. 3. Colonizing ability and movement of Clavibacter michiganensis subsp. nebraskensis as estimated by distance traveled on both sides of inoculation site (OPD) over time in susceptible and resistant maize hybrids. Mean bacterial titer $(n=9)$ was determined from combined data of three experiments at every $5 \mathrm{~cm}$ along proximal $(P)$ and distal (D) part of leaf from inoculation site at four sampling periods (4 to 22 days postinoculation [DPI]). C. michiganensis subsp. nebraskensis population growth and movement were unrestricted to the distal end of the site of inoculation in a resistant hybrid compared with the proximal end. Bars indicate standard errors.

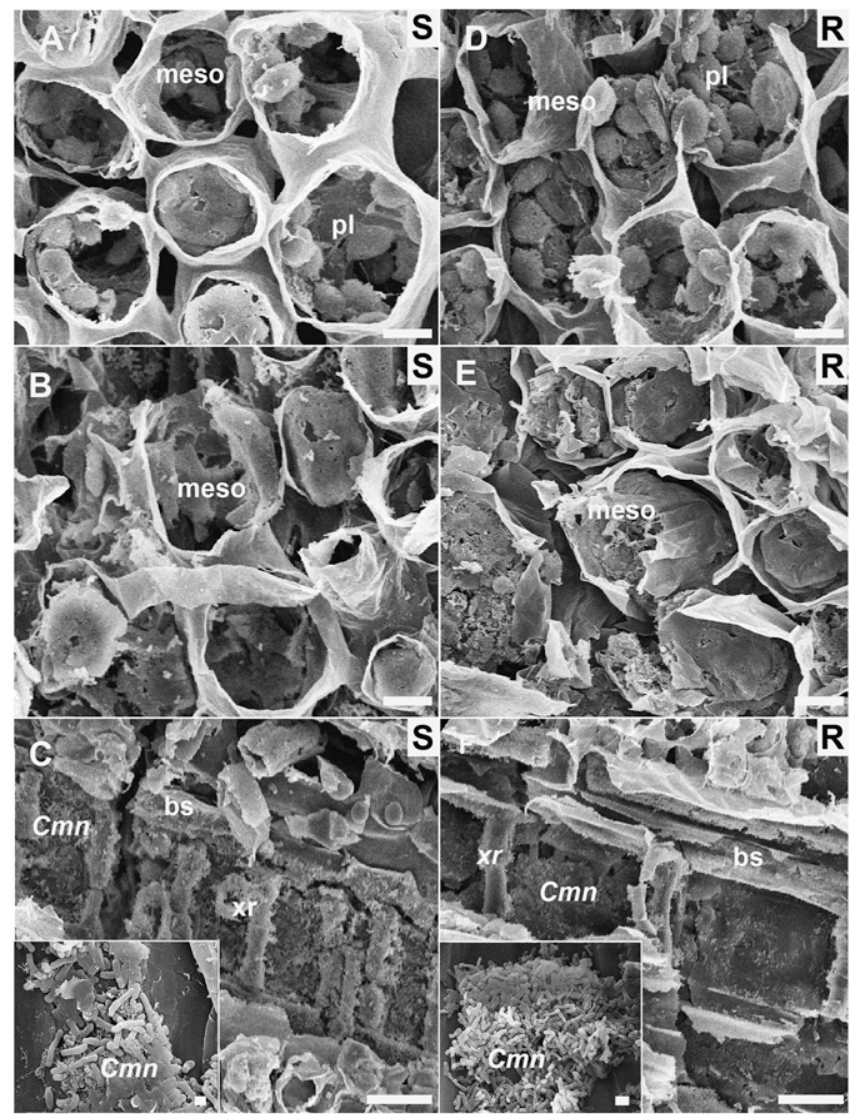

Fig. 4. Representative scanning electron microscopy images of leaf fractures of maize hybrids at 10 days postinoculation (dpi). A, Healthy mesophyll (meso) of uninoculated susceptible (S) leaf and $D$, uninoculated resistant (R) leaf showing organelles, including plastids (pl), with starch grains within cells. B, Mesophyll of inoculated S leaves. E, Mesophyll of inoculated R leaves. C, View of a metaxylem vessel of $\mathbf{S}$ leaf with Clavibacter michiganensis subsp. nebraskensis $(\mathrm{Cmn})$ (insert) at $10 \mathrm{dpi}$. Leaf subsamples were taken from $5 \mathrm{~cm}$ from inoculation site within lesions; bs = bundle sheath and $\mathrm{xr}=$ xylem ring. $F$, View of a metaxylem vessel of $R$ leaf with C. michiganensis subsp. nebraskensis at $10 \mathrm{dpi}$ taken from $1 \mathrm{~cm}$ from inoculation site within lesion. Bars: $A, B, D$, and $E, 20 \mu \mathrm{m} ; C$ and F, $100 \mu \mathrm{m} ; C$ insert, $2 \mu \mathrm{m}$; and $F$ insert, $5 \mu \mathrm{m}$. 
correlated with smaller lesion sizes (Hammerschmidt and Nicholson 1977). In the same study, the phenolic content was higher in resistant and hypersensitive-resistant maize inbred lines, suggesting that phenolics were implicated in the process of lesion reduction. We tested crude methanol extracts from 4- and 10-dpi leaves of the R hybrid in plate-inhibition assays with Clavibacter michiganensis subsp. nebraskensis but no antibacterial activity was detectable (results not shown). Furthermore, we compared total phenolic content of both hybrids at 4 and 10 dpi using three different extraction methods but did not detect differences in contents. Therefore, we concluded that phenolics may not be involved in resistance mechanisms to C. michiganensis subsp. nebraskensis.

The SEM images of leaf fractures taken within lesions showed dense masses of bacteria in the vasculature (mostly in the xylem vessels) and mesophyll, indicating the ability of the pathogen to colonize and multiply in both hybrids. Fewer bacteria were observed in the leaf tissues $1 \mathrm{~cm}$ from the edge of the lesion in the R hybrid compared with the $\mathrm{S}$ hybrid, confirming the results from the plate count experiments. In the xylem of both hybrids, $C$. michiganensis subsp. nebraskensis bacteria were more prevalent at the spiral and annular rings, as well as the inner walls of the vessels. Disruption of the middle lamellae and loss of cellular integrity in the $S$ hybrid occurred earlier than in the R hybrid. In both cases, this disruption might have resulted from high bacterial densities through their extensive multiplication in the xylem lumen and the intercellular spaces of the mesophyll. However, production of cell-wall-degrading enzymes cannot be ruled out. C. michiganensis subsp. nebraskensis showed preference for the metaxylem at the initial stages of infection even when infection was accomplished via the cut-inoculation method that

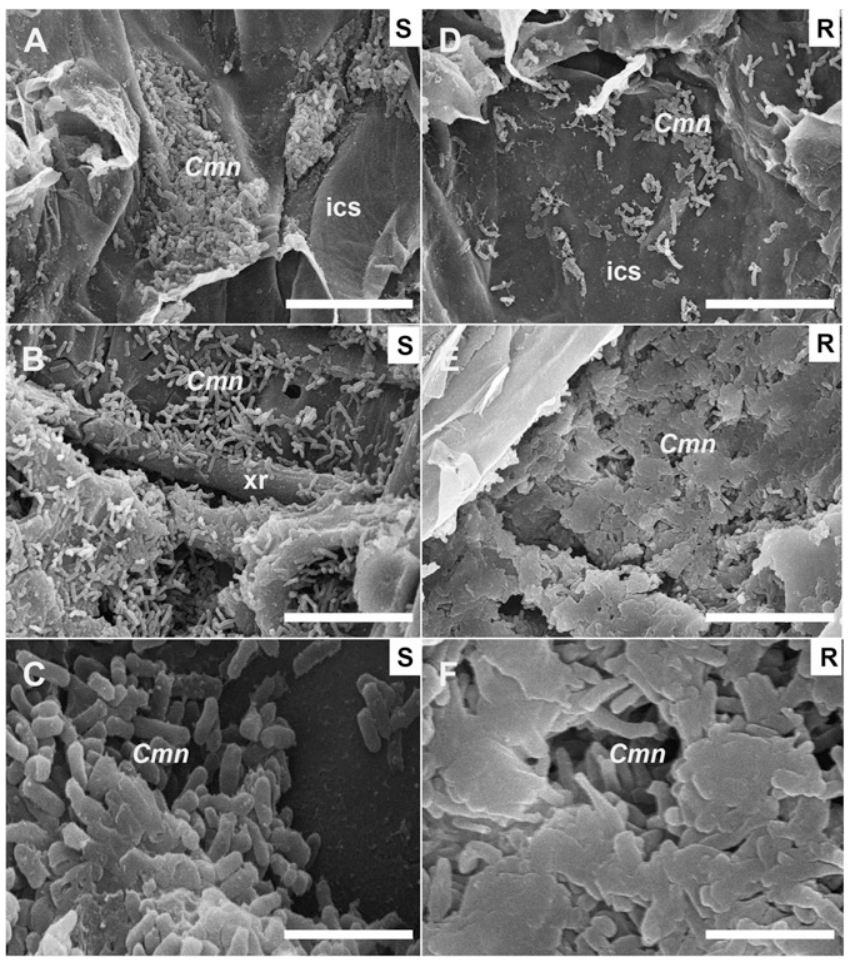

Fig. 5. Scanning electron microscopy leaf fracture images of maize leaves at 10 days postinoculation (dpi) inoculated with Clavibacter michiganensis subsp. nebraskensis $(\mathrm{Cmn})$. A, Bacteria located in intercellular spaces of mesophyll cells (ics) of inoculated susceptible (S) leaf. D, Bacteria in intercellular space (ics) of mesophyll of resistant (R) hybrid. B, Appearance of $\mathrm{C}$. michiganensis subsp. nebraskensis in xylem vessel in $\mathbf{S}$ hybrid at $10 \mathrm{dpi}$; $\mathrm{xr}=$ xylem ring. $\mathbf{E}$, Appearance of $\mathbf{C}$. michiganensis subsp. nebraskensis in xylem vessel of $\mathrm{R}$ hybrid. C, Close-up view of $C$. michiganensis subsp. nebraskensis in metaxylem shows normal bacteria cells without a matrix. F, Close-up view of $C$. michiganensis subsp. nebraskensis in metaxylem show cells associated with thick amorphous matrix (am). Bars: A, B, D, and $E, 10 \mu \mathrm{m} ; C$ and $F, 2 \mu \mathrm{m}$. Colonization pattern shown was typical of all samples examined. allowed access to a larger surface area of tissue. Contrary to $C$. michiganensis subsp. nebraskensis, similar experiments showed that C. michiganensis subsp. michiganensis had a clear preference for the protoxylem even at later stages of infection in tomato plants (Chalupowicz et al. 2012). This distinction between the two vascular wilt pathogens may be due to differences in the structure and organization of the vasculature in monocotyledons compared with dicotyledons.

Because maize hybrids showed similar disease development and yield to Goss's wilt and Stewart's wilt pathogens, it was suggested that similar management decisions encompassing resistant germplasm might be used for both pathogens (Pataky 1985; Pataky et al. 1988; Suparyono and Pataky 1989). Braun $(1982,1990)$ showed that the structural responses of resistant maize inbred lines to infection by $P$. stewartii (causal agent of Stewart's wilt) were very distinct from susceptible hybrid responses. In our experiments, we noted similarities in the reduced rate of lesion expansion in the resistant host compared with the susceptible host. We also observed a reduced rate of pathogen growth as well as host responses that limited or localized the pathogen, which presumably account for the reduced rate of lesion length expansion in the R hybrid. Even though we observed physical changes similar to those observed by Braun, further work needs to be done to elucidate these similarities, particularly at the molecular level, because $P$. stewartii is a gram-negative bacterium while C. michiganensis subsp. nebraskensis is gram positive.

Our studies showed that $C$. michiganensis subsp. nebraskensis colonized the metaxylem vessels with a high degree of spatial specificity by preferentially colonizing the xylem annular and spiral rings to form a foundational layer for subsequent attachment of cells progressing into the lumen. This type of colonization has been described for plant-pathogenic bacteria, in which adhesion and host colonization is governed by quorum sensing (Koutsoudis et al. 2006). It is possible that symptom induction, movement, and colonization of the host by $C$. michiganensis subsp. nebraskensis could be regulated by a quorum-sensing system. The fact that $C$. michiganensis subsp. nebraskensis is able to infect the $\mathrm{R}$ hybrid and cause blight lesions is an indication that it is able to overcome the basal defenses of this hybrid. Our results suggest a resistant mechanism in which the bacterial population is kept below the required threshold in the $\mathrm{R}$ hybrid. Furthermore, the fact that the $\mathrm{R}$ hybrid is able to restrict and limit the movement of $C$. michiganensis subsp. nebraskensis in the xylem vessels may suggest the presence of PRR that are able to perceive conserved C. michiganensis subsp. nebraskensis structures or peptides and, thereby, trigger resistance. Additional research that explores both the PAMP and the PRR in this pathosystem would contribute to our understanding of the interaction of gram-positive bacteria with monocot hosts.

\section{Acknowledgments}

This research project was accomplished with funds from Monsanto. We thank T. Stewart, Microscopy and Nano-Imaging Facility (MNIF), a Biotechnology and Life Sciences Instrumentation Center, Iowa State University, for preparing the leaf fracture samples for SEM.

\section{Literature Cited}

Abendroth, L. J., Elmore, R. W., Boyer, M. J., and Marlay, S. K. 2011. Corn Growth and Development. PMR 1009. Iowa State Extension, Ames.

Ade, J., and Innes, R. W. 2007. Resistance to bacterial pathogens in plants. In: Encyclopedia of Life Sciences 1-6. Online publication. John Wiley \& Sons, Ltd.

Balmer, D., Planchamp, C., and Mauch-Mani, B. 2013. On the move: Induced resistance in monocots. J. Exp. Bot. 64:1249-1261.

Beckman, C. H. 2000. Phenolic-storing cells: Keys to programmed cell death and periderm formation in wilt disease resistance and in general defense responses in plants? Physiol. Mol. Plant Pathol. 57:101-110.

Braun, E. J. 1982. Ultrastructural investigation of resistant and susceptible maize inbreds infected with Erwinia stewartii. Phytopathology 72:159-166.

Braun, E. J. 1990. Colonization of resistant and susceptible maize plants by Erwinia stewartii strains differing in exopolysaccharide production. Physiol. Mol. Plant Pathol. 36:363-379.

Calub, A. G., Compton, W. A., Gardner, C. O., and Schuster, M. 1974. Reaction of 113 corn (Zea mays) genotypes to leaf freckles and wilt. Plant Dis. Rep. 58:956-960.

Carson, M. L., and Wicks, Z. W., III. 1991. Relationships between leaf freckles and wilt severity and yield losses in closely related maize hybrids. Phytopathology 81:95-98. 
Chalupowicz, L., Zellermann, E. M., Fluegel, M., Dror, O., Eichenlaub, R., Gartemann, K.-H., Savidor, A., Sessa, G., Iraki, N., Barash, I., and ManulisSasson, S. 2012. Colonization and movement of gfp-labeled Clavibacter michiganensis subsp. michiganensis during tomato infection. Phytopathology 102:23-31.

Chen, C.-Y., Nace, G. W., and Irwin, P. L. 2003. A 6x6 drop plate method for simultaneous colony counting and MPN enumeration of Campylobacter jejuni, Listeria monocytogenes, and Escherichia coli. J. Microbiol. Methods 55:475-479.

Claflin, L. E. 1999. Goss's bacterial wilt and blight. Pages 4-5 in: Compendium of Corn Diseases, 3rd ed. D. G. White, ed. American Phytopathological Society, St. Paul, MN.

Davis, M. J., Gillespie, A. G., Vidaver, A. K., and Harris, R. W. 1984. Clavibacter: A new genus containing some phytopathogenic coryneform bacteria, including Clavibacter xyli subsp. xyli sp. nov., subsp. nov., and Clavibacter xyli subsp. cynodontis subsp. nov., pathogens that cause ratoon stunting disease of sugarcane and bermudagrass stunting disease. Int. J. Syst. Bacteriol. 34: 107-117.

Givens, W. A., Shaw, D. R., Kruger, G. R., Johnson, W. G., Weller, S. C., Young, B. G., Wilson, R. G., Owen, M. D. K., and Jordan, D. 2009. Survey of tillage trends following the adoption of glyphosate-resistant crops. Weed Technol. 23:150-155.

Hammerschmidt, R., and Nicholson, R. L. 1977. Resistance of maize to anthracnose: Changes in host phenols and pigments. Phytopathology 67: 251-258.

Hollier, C. A., Singh, R. A. and Frazier, R. 2014. Goss's wilt in Louisiana: Incidence, severity and loss. (Abstr.) Phytopathology 104(Suppl. 2):S2.5.

Ivanoff, S. 1936. Resistance to bacterial wilt of open-pollinated varieties of sweet, dent and flint corn. J. Agric. Res. 53:917-926.

Ivanoff, S. S., and Riker, A. J. 1936. Resistance to bacterial wilt of inbred strains and crosses of sweet corn. J. Agric. Res. 53:927-954.

Jackson, T. A., Harveson, R. M., and Vidaver, A. K. 2007. Goss's bacterial wilt and leaf blight of corn. Online publication. Nebraska Extension Publications. http://extensionpublications.unl.edu/assets/html/g1675/build/g1675.htm

Jensen, W. A. 1962. Botanical Histochemistry. Principles and Practice. W. H. and Co., San Francisco, London.

Jones, J. D., and Dangl, J. L. 2006. The plant immune system. Nature 444:323-329.

Korus, K. A., Timmerman, A. D., French-Monar, R. D., and Jackson, T. A. 2011. First report of Goss's bacterial wilt and blight (Clavibacter michiganensis subsp. nebraskensis) on corn in Texas. Plant Dis. 95:73.
Koutsoudis, M. D., Tsaltas, D., Minogue, T. D., and von Bodman, S. B. 2006 Quorum-sensing regulation governs bacterial adhesion, biofilm development, and host colonization in Pantoea stewartii subspecies stewartii. PNAS 103 5983-5988.

Langemeier, C. B., Jackson-Ziems, T. A., and Kruger, G. R. 2012. Four common foxtail species are alternate hosts of Clavibacter michiganensis subsp. nebraskensis, causal agent of Goss's bacterial wilt and blight of Zea mays. (Abstr.) Phytopathology 102(Suppl. 5):S5.6.

Malvick, D., Syverson, R., Mollov, D., and Ishimaru, C. A. 2010. Goss's bacterial blight and wilt of corn caused by Clavibacter michiganensis subsp. nebraskensis occurs in Minnesota. Plant Dis. 94:1064.

Pataky, J. K. 1985. Relationships among reactions of sweet corn hybrids to Goss's wilt, Stewart's bacterial wilt, and northern corn leaf blight. Plant Dis. 69:845-848.

Pataky, J. K., Headrick, J. M., and Suparyono. 1988. Classification of sweet corn hybrid reactions to common rust, northern leaf blight, Stewart's wilt, and Goss's wilt and associated yield reductions. Phytopathology 78:172-178.

Robertson, A., and Jesse, L. 2008. Goss's wilt prevalent in western Iowa. Online publication. Integrated Crop Management News, Iowa State University, Ames. http://lib.dr.iastate.edu/cropnews/791/

Ruhl, G., Wise, K., Creswell, T., Leonberger, A., and Speers, C. 2009. First report of Goss's bacterial wilt and leaf blight on corn caused by Clavibacter michiganensis subsp. nebraskensis in Indiana. Plant Dis. 93:841

Schuster, M. L. 1975. Leaf freckles and wilt of corn incited by Corynebacterium nebraskense Schuster, Hoff, Mandel, Lazar. Res. Bull. 270. The Agricultura Experiment Station Institute of Agriculture and Natural Resources, University of Nebraska, Lincoln.

Schuster, M. L., Compton, W. A., and Hoff, B. 1972. Reaction of corn inbred lines to the new Nebraska leaf freckles and wilt bacterium. Plant Dis. Rep. 56:863-865.

Smidt, M., and Vidaver, A. K. 1986. Population dynamics of Clavibacter michiganensis subsp. nebraskense in field-grown dent corn and popcorn. Plant Dis. 70:1031-1036.

Suparyono, and Pataky, J. K. 1989. Influence of host resistance and growth stage at the time of inoculation on Stewart's wilt and Goss's wilt development and sweet corn hybrid yield. Plant Dis. 73:339-345.

Treat, C. L., and Tracy, W. F. 1990. Inheritance of resistance to Goss's wilt in sweet corn. J. Am. Soc. Hortic. Sci. 115:672-674.

Treat, C. L., Tracy, W. F., Drolsom, P. N., and Coors, J. G. 1990. The inheritance of resistance to Goss's wilt in maize. Crop Sci. 30:893-896.

Vidaver, A. K. 1982. The plant pathogenic corynebacteria. Annu. Rev. Microbiol. 36:495-517. 